\title{
Omental cysts mimickıng acute abdomen in a 3-year-old girl
}

\author{
Volkan Sarper Erikci ${ }^{1}$, Elif Abay ${ }^{2}$ and Gökhan Köylüoğlu ${ }^{* 3}$ \\ ${ }^{1}$ Attending Pediatric Surgeon, Associate Professor of Pediatric Surgery, Tepecik Training Hospital, Izmir, Turkey \\ ${ }^{2}$ Trainee in Pediatric Surgery, Tepecik Training Hospital, Izmir, Turkey \\ ${ }^{3}$ Professor of Pediatric Surgery, Chief Department of Pediatric Surgery, Tepecik Training Hospital, Izmir, Turkey
}

\begin{abstract}
Omental cysts (OC) are rare abdominal pathology which are difficult to diagnose preoperatively. The most common presenting symptoms are abdominal distension and abdominal pain. We present a case of $\mathrm{OC}$ in a 3-year-old girl who presented with acute abdominal symptoms. The cyst was totally excised and histological examination revealed an $\mathrm{OC}$ with endothelial lining and serous fluid inside. A patient with OC in this report is presented and discussed with regard to the foregoing literature.
\end{abstract}

\section{Introduction}

Omental cysts (OC) are rare intra-abdominal pathologies with only about 150 cases reported till now [1]. These are mostly benign lesions. With regard to Japanese literature these masses occur more frequently in men than in women whereas there is a female predominance in Western countries [2]. This report describes a case of OC presented with acute abdomen.

\section{Patient}

A previously healthy 3-year-old girl was evaluated because of an acute abdominal pain with 3 days duration with bilious vomiting. Her physical examination revealed generalized peritoneal tenderness. The laboratory tests were normal except a leukocytosis $\left(18.300 / \mathrm{mm}^{3}\right)$ and an increase in CRP level $(65.8 \mathrm{mg} / \mathrm{L})$. X-ray of the abdomen was inconclusive with no signs of intestinal obstruction (Figure 1). Ultrasonography (US) demonstrated generalized multiseptated free fluid occupying hypogastric area. The patient underwent surgery with a probable diagnosis of perforated appendicitis. Intraoperative findings showed a multiloculated cystic mass of $12 \times 10 \mathrm{~cm}$ in diameter arising form the greater omentum (Figure 2 and 3). Total excision of the mass was performed. The histopathological examination revealed a multicystic mass compatible with omental cyst and accompanying chronic inflamatory changes. Following an uneventful postoperative course, the patient was discharged on the $3^{\text {rd }}$ postoperative day. Control US taken on the $3^{\text {rd }}$ postopertive month is normal and the patient has no symptoms or signs related to the operation.

\section{Discussion}

OCs are benign abdominal anomalies with uncertain etiologies. They are assumed to represent benign proliferation of ectopic lymphatics that lack communication with the normal lymphatic system [3]. Since the first description of an OC in 1852 by Gairdner, this entity has been reported very scarcely [4-6]. The incidence of mesenteric and OCs is 1 in 20000 among children and lower in infants and of these cystic masses $2.2 \%$ are OCs [7]. About 150 cases have been reported upto now, $25 \%$ of which have been detected in children less than 10 years of age $[1,8]$.
Different etiological factors have been proposed for these masses including benign proliferation of mesenteric lymphatics, failed fusion of the mesenteric leaves, and deficiency of the lymphatico-venous shunts [8-10]. Other etiologic hypotheses include trauma, neoplasia and degeneration of the lymph nodes [5]. These cysts may present either incidentally or with acute abdominal pain with abdominal distention and possible ascites $[2,8,11]$. The location and the size of the cyst have an impact on the spectrum of symptomatology. Disorders related to respiratory or urinary system, in addition to symptoms of portal vein compression may also be seen due to cyst enlargement. Like the case presented in this report, patients under 10 years of age are

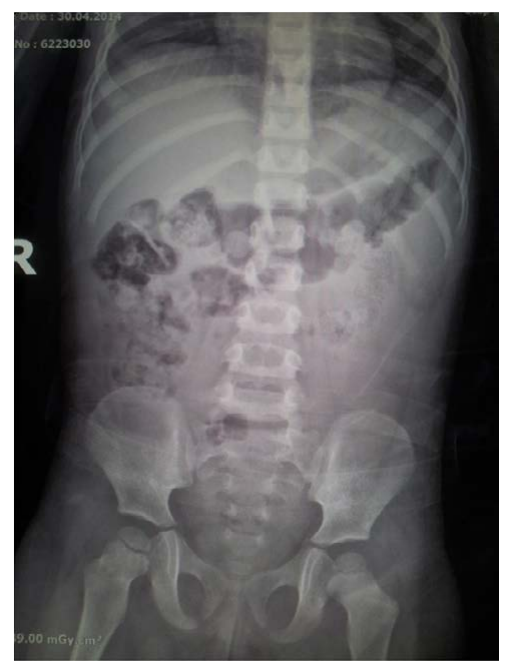

Figure 1. Plain X-ray of the abdomen showing distended bowel loops and faecal material. Note there is no evidence of bowel obstruction or perforation.

Correspondence to: Volkan Sarper Erikci, Kazım Dirik Mah. Mustafa Kemal Cad. Hakkıbey apt. No:45 D.10 35100 Bornova-İzmir, Tel: +90 542 4372747, Office: +90 232 4696969, Fax: +902324330756

Received: February 03, 2017; Accepted: February 16, 2017; Published: February 18,2017 


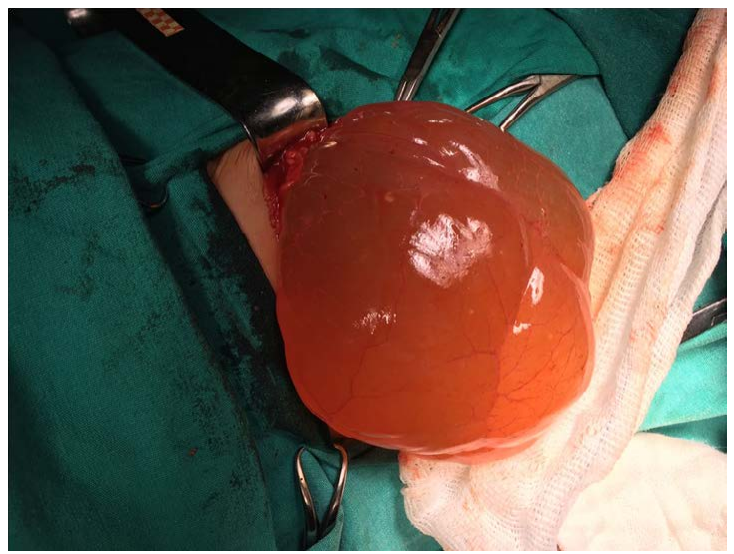

Figure 2. Operative view of omental cyst arising from greater omentum. (Arrow: cystic mass).

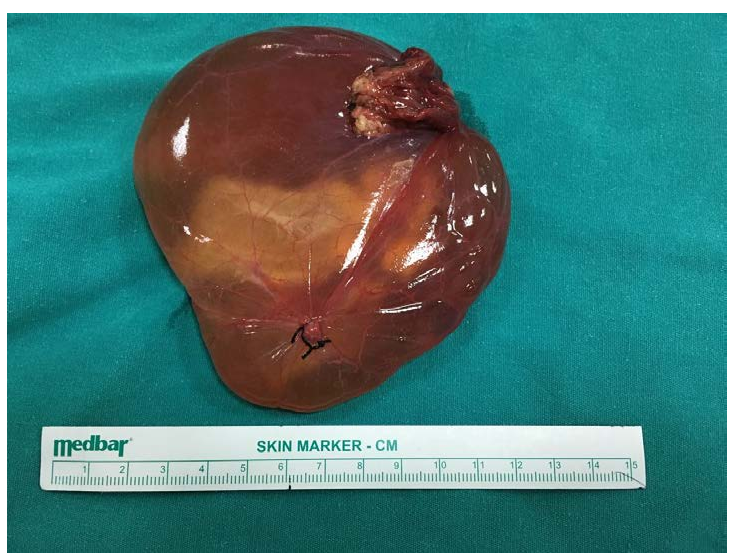

Figure 3. Omental cyst after excision.

different from older ones having shorter duration of symptoms, higher emergent surgical intervention rates and lower recurrences [12]. Of the children with OCs $11-19 \%$ present with acute abdominal symptoms including torsion, bleeding or rupture of the cyst [2]. Our case with a 3 days duration of symptoms, had a large OC originating from the greater omentum in the region of transverse colon and splenic hilus. The cyst with a dimension of $10 \times 12 \mathrm{~cm}$ had multiloculated appearance containing serosanginous liquid inside without solid component and was totally excised. Histopathological examination revealed findings compatible with OC.

From the pathological point of view, these cysts can be unilocular or multilocular majority of which are mesothelial and lined by mesothelial and endothelial cells [13]. Most contain serous fluid leading to the misdiagnosis of ascites $[9,13,14]$.

An accurate preoperative diagnosis of OCs is usually difficult and a correct preoperative diagnosis of OC has been reported in 13$25 \%$ of cases. Clinicians dealing with these children should have a high index of suspicion and perform a careful physical examination. With the symptoms of peritoneal irritation and bilious vomiting, our preoperative diagnosis was a perforated appendicitis which turned out to be later on an OC after emergent surgical intervention.

Radiological imaging modalities are helpful in diagnosing these cysts preoperatively. US has been reported as the initial tool in all the cases. If performed by an experienced radiologist, US has been reported to be the most reliable diagnostic modality for detecting these lesions [15]. Sonographic findings frequently include multiloculated, fluid filled and predominantly cystic lesions $[9,10,16]$. There were similar sonographic findings in our case preoperatively. Magnetic resonance imaging (MRI) and computerised tomography (CT) may provide additional information about the exact extension, and interior properties of the lesion $[9,10,16]$. However because of exposed irradiation during CT and long time period and sedation needed for MRI, these diagnostic work-up tools should not be used routinely and their usage are recommended in suspect cases when needed.

The preferred treatment of OC is complete excision and resection of the bowel is rare. Laparoscopic management and hand-assisted laparoscopic excision and aspiration has also been advocated by some authors $[8,17]$. But it is stated that if it is found not to be benign, risk of spillage during laparoscopy should be kept in mind. Open surgical intervention has been suggested to avoid the risk of spreading the cyst contents [2]. No matter which type of surgical intervention is performed, total excision should be the goal for avoiding recurrence of these cystic masses. Other treatment options including aspiration, drainage and irradiation give poor results $[12,18,19,20]$. Injection of OK-432 or marsupialization have also been advocated for unresectable cysts $[21,22]$.

The main complication after surgical treatment is recurrence which has been reported to occur in $9.5 \%$ of patients especially when resection is incomplete [18]. Other complications include hemorrhage, torsion, infection, rupture and symptoms related to pressure effects of the cystic mass to adjacent structures. Despite limited follow-up period of 6 months there is no recurrence in our patient and she is disease free with an uneventful follow-up.

During childhood period, OCs are rarely seen and can mimic other disease states. Surgical treatment, if performed early, can prevent life-threatening complications such as torsion, rupture, bleeding and infection. The possibility of this diagnosis should be kept in mind for the patients with acute abdominal symptoms and managed accordingly.

\section{References}

1. Vanek VW, Phillips AK (1984) Retroperitoneal, mesenteric, and omental cysts. Arch Surg 119: 838-842. [Crossref]

2. Uramatsu M, Saida Y, Nagao J, Takase M, Sai K, et al. (2001) Omental cyst: report of a case. Surg Today 31: 1104-1106. [Crossref]

3. Kumar S, Agrawal N, Khanna R, Khanna AK (2009) Giant lymphatic cyst of omentum a case report. Cases J 2: 23. [Crossref]

4. Tan JJ, Tan KK, Chew SP (2009) Mesenteric cysts: an institution experience over 14 years and review of literature. World J Surg 33: 1961-1965. [Crossref]

5. Egozi EI, Ricketts RR (1997) Mesenteric and omental cysts in children. Am Surg 63 287-290. [Crossref]

6. Kurtz RJ, Heimann TM, Holt J, Beck AR (1986) Mesenteric and retroperitoneal cysts Ann Surg 203: 109-112. [Crossref]

7. Karhan AN, Soyer T, Gunes A, Talim B, Karnak I, et al. (2016) Giant Omental Cyst (Lymphangioma) Mimicking Ascites and Tuberculosis. Iran J Radiol 13: e31943. [Crossref]

8. Pampal A, Yagmurlu A. (2012) Successful laparoscopic removal of mesenteric and omental cysts in toddlers: 3 cases with a literature review. J Pediatr Surg 47(8): e5-e8. [Crossref]

9. Adikibi BT, Wood R, Pillay K, Millar AJ (2013) Omental cyst presenting with profound anaemia. Afr J Paediatr Surg 10: 180-184. [Crossref]

10. Motie MR, Asadi M (2011) Large omental cyst: a case report and review of the literature. Acta Med Iran 49: 690-693. [Crossref]

11. Hebra A, Brown MF, McGeehin KM, Ross AJ 3rd (1993) Mesenteric, omental, and retroperitoneal cysts in children: a clinical study of 22 cases. South Med J 86: 173-176. [Crossref] 
12. Kurtz RJ, Heimann TM, Holt J, Beck AR (1986) Mesenteric and retroperitoneal cysts. Ann Surg 203: 109-112. [Crossref]

13. Walker AR, Putnam TC (1973) Omental, mesenteric, and retroperitoneal cysts: a clinical study of 33 new cases. Ann Surg 178: 13-19. [Crossref]

14. Joshi N, Yadav S, Singh B, Gupta A (2010) Omental cyst presenting as tubercular ascites. J Infect Dev Ctries 4: 183-186. [Crossref]

15. Senocak ME, GÃndoÄŸdu H, BÃyÃkpamukÃßu N, HiÃßsÃ Inmez A (1994) Mesenteric and omental cysts in children. Analysis of nineteen cases. Turk J Pediatr 36: 295-302. [Crossref]

16. Kokhanovsky N, Nachtigal A, Reindorp N, Shinhar D, Zeina AR (2014) Giant omental hemorrhagic cyst presenting as acute hemorrhagic anemia in a 21-month-old infant. Pediatr Emerg Care 30: 188-190. [Crossref]

17. Motie MR, Asadi M (2011) Large omental cyst: a case report and review of the literature. Acta Med Iran 49: 690-693. [Crossref]

18. Steyaert H, Guitard J, Moscovici J, Juricic M, Vaysse P, et al. (1996) Abdominal cystic lymphangioma in children: benign lesions that can have a proliferative course. $J$ Pediatr Surg 31: 677-680. [Crossref]

19. Roisman I, Manny J, Fields S, Shiloni E (1989) Intra-abdominal lymphangioma. $B r J$ Surg 76: 485-489. [Crossref]

20. Konen O, Rathaus V, Dlugy E, Freud E, Kessler A, et al. (2002) Childhood abdominal cystic lymphangioma. Pediatr Radiol 32: 88-94. [Crossref]

21. Oliveira C, Sacher P, Meuli M (2010) Management of prenatally diagnosed abdominal lymphatic malformations. Eur J Pediatr Surg 20: 302-306. [Crossref]

22. Luzzatto C, Lo Piccolo R, Fascetti Leon F, Zanon GF, Toffolutti T, et al. (2005) Further experience with OK-432 for lymphangiomas. Pediatr Surg Int 21: 969-972. [Crossref]

Copyright: ( 2017 Erikci VS. This is an open-access article distributed under the terms of the Creative Commons Attribution License, which permits unrestricted use, distribution, and reproduction in any medium, provided the original author and source are credited. 